\title{
SIMULATION DYNAMIC PROCESSES OF RAIL VEHICLE AND RAIL WITH IRREGULARITIES
}

\author{
Marijonas Bogdevicius, Rasa Zygiene \\ Vilnius Gediminas Technical University, Department of Transport and Technological Equipment \\ Plytinès 27, LT-10105, Vilnius, Lithuania \\ tel.: +37052744782 \\ e-mail:marius@vgtu.lt,rasazz@gmail.com
}

\begin{abstract}
The work presents research of defective railway wheel and rail dynamics and mathematical model of system "Railway vehicle wheel - track". An assumption was made that the Rail $R-65$ and railway wheel with flats are with unevenness. The aim of this investigation is to identify the contact forces resulting from the wheel/rail contact at the various defects. Rail track dynamics is described by finite element method, while soil and wagon dynamics is described by the discrete elements. The mathematical model is to assess physical and mechanical properties, roughness of wheel and rail surface, and their geometry. In the mathematical model of the rail is evaluated: the impact of axial force, the initial deformation of rail, the foundation of soil, the gap between sleeper and rail. Profile of railway wheel is defined as a function of radius variable depending on the polar angle and described by Fourier series. In this mathematical model of railway wheel and rail contact area is divided into small sections, where the force is set in contact using the Hertz theory. Total system of non-linear equations of motion is solved by applying the Newton-Raphson method.

The speed of the train is $100 \mathrm{~km} / \mathrm{h}$ and static load on the rail is $100 \mathrm{kN}$. The flat of the wagon wheel is $L=100 \mathrm{~mm}$. Numerical results of contact problem are obtained. Duration of contact is nearly equal to period during which the wheel set passes a half of the flat length. The contact force operating the wheelset is equal to approximately 1.0 MN. Maximum value of the sleeper acceleration is equal $410 \mathrm{~g}$.
\end{abstract}

Keywords: railway wheel, rail, flat, contact, dynamics, vibration

\section{Introduction}

Rail is the main element that determines the speed of train on the railway. Reasons why defects of the wheel/rail irregularities are being emerged may be different. Increasing number of defects in track and wheels may endanger the safety of train traffic, the environment, human health and life.

Many created $[1,2]$ mathematical models include railway vehicle and track. Models evaluate railway vehicle velocity, wheel and rail unevenness, physical and mechanical characteristics of soil.

While modelling railway vehicle wagon-track system, the track is being modelled as elastic base and $[3,4]$ tangential tensions in wheel-rail interaction are defined. The rail is analysed using [5-7] Timoshenko method. While analysing track stiffness, it is determined [8], that track stiffness varies throughout track profile due to constantly changing soil properties and factors that affect it, which influences track decomposition.

3D models are created with the help of computer-based modelling programs, in which various modes of dynamic strain influence on the system are analysed [9]. It is determined that by reducing resonance of track elements, it is possible to create the formation of rail, sleeper and fractional ballast. A model was created and experiment [10] to determine the vibrations of railway ballast was accomplished.

While creating [11] 3D model, quasi-Hertz and finite element (FE) methods were used. Research results given in this article describe distribution of stress in wheel and rail contact zones.

While wagon is rolling on the rails, dynamic effects, which are created by major velocities or 
their alteration, appear and additional inertias, depending on the distribution of wagon masses, decrement forces, impact loads, vibrations, resonance and etcetera, are composed. Dynamical nature of load is affected not only by wheel - track interaction [12-15]. The dynamism of force can be influenced by the incompletion or fault in production of rail and wheel.

Weariness of wheel and rail is dependent on primary profile [16]. In order to get the weariness norm dependence on contact, laboratory experiments must be made. Archard's wear model $[17,18]$ is used to calculate the depth of weariness on wheel surface.

Numerical mathematical model and experiment results have shown that during constant change of load on railway vehicle, maximum displacement increases along with the velocity of force.

\section{Mathematical model of rail and rail wheel contact}

The aim of this investigation is to identify the contact forces resulting from the wheel/rail contact at the various defects. A mathematical model was created in order to analyse the main railway wheel defects.

Profile of railway wheel is defined as a function of radius variable depending on the polar angle. Radius function $\mathrm{R}(\varphi)$ of the wheel profile is described by Fourier series.

While analysing interaction of rail-wheel it is assumed that: the profiles of rail-wheel are with potential defects; the unevenness of the rail surface are possible.

In the mathematical model of railway wheel and rail, it is assessed: micro-unevenness, localized slip, normal and tangential forces and moments of forces along the length of contact between the wheel and rail.

In this mathematical model, the length of the contact is divided into small sections, where the force is set in contact using the Hertz theory.

The unevenness of the rail and the contact between the rail and wheel are analysed in this mathematical model Fig. 1 and Fig. 2.
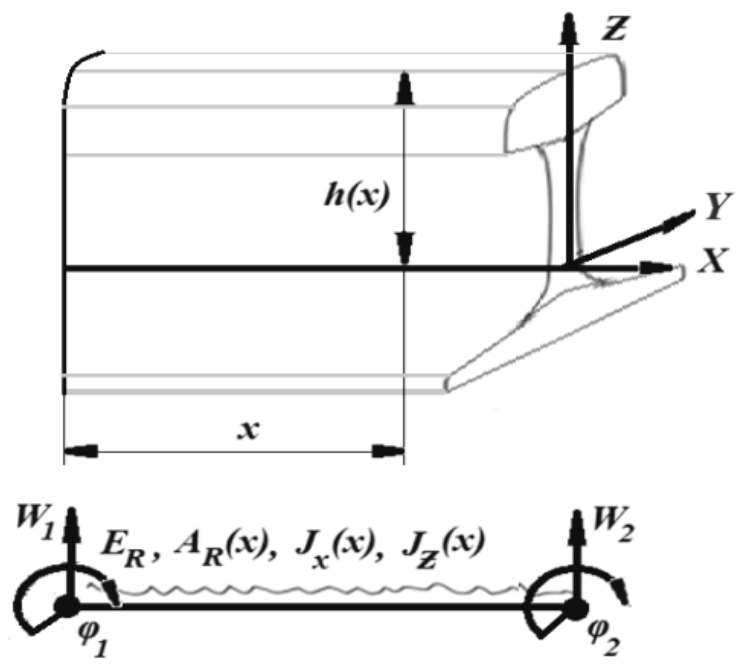

Fig. 1. Parameters assessing the rail unevenness

General equation system of all movement system is equal to:

$$
[M]\{\ddot{q}\}+[C]\{\dot{q}\}+[K]\{q\}+\left\{F_{N L}(q, \dot{q})\right\}=\{F(t)\},
$$

where:

$\{q\},\{\dot{q}\},\{\ddot{q}\} \quad$ - displacement, acceleration and speed vectors, respectively,

$[M],[C],[K],\left\{F_{N L}(q, \dot{q})\right\},\{F(t)\}$ - mass, damping and stiffness matrices, nonlinear force load and weight force load vectors, respectively. 


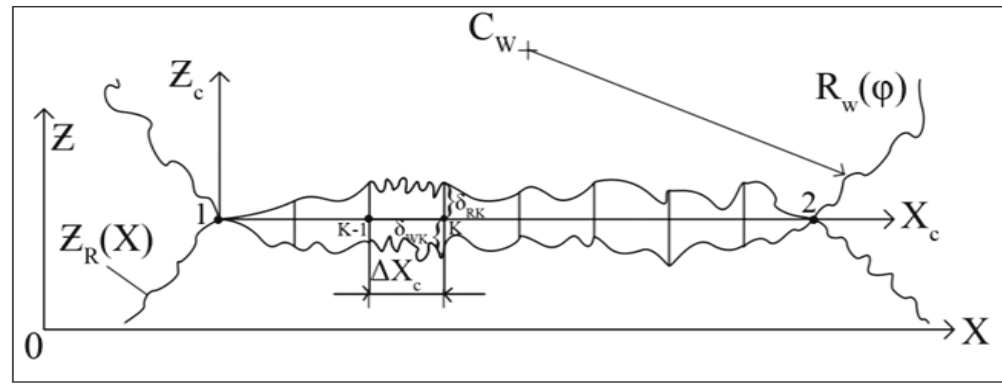

Fig. 2. Parameters assessing the wheel/rail contact

\section{Numerical results of dynamic process in the system "Railway vehicle wheel - track"}

In order to compile the mathematical model of the system "Railway vehicle wheel-track" data of a four-axle wagon 12-9780 was used. It is assumed that the wagon is moving at a speed of 100 $\mathrm{km}$ per hour. The flat of the wagon wheel is $\mathrm{L}=100 \mathrm{~mm}$. Static load on the rail is $100 \mathrm{kN}$. The rail is R65. The distance between sleepers is $0.5435 \mathrm{~m}$. The distance between sleepers is divided into 10 beam finite elements. Integration time step is $\Delta t=10^{-6} \mathrm{~s}$. The parameters of developed system are presented in Tab. 1.

Tab. 1. Data Calculations. Track and vehicle system

\begin{tabular}{|c|c|c|c|}
\hline Definition & Notation & Definition & Notation \\
\hline axial load force & $F_{x}=0 \mathrm{kN}$ & ballast damping coefficient: & $C_{s 11, i, j}=10 \mathrm{kNs} / \mathrm{m}$ \\
\hline $\begin{array}{l}\text { second moment of area of } \\
\text { rail about } Y\end{array}$ & $J_{R}=3.54 \cdot 10^{-5} \mathrm{~m}^{4}$ & $C_{s 22, i, j}=13 \mathrm{kNs} / \mathrm{m}$ & $C_{s 33, i, j}=15 \mathrm{kNs} / \mathrm{m}$ \\
\hline il cross section area & $A_{R}=82.65 \cdot 10^{-4} \mathrm{~m}^{2}$ & $C_{s 01}=90 \mathrm{kNs} / \mathrm{m}$ & $C_{s 12}=70 \mathrm{kNs} / \mathrm{m}$ \\
\hline $\begin{array}{l}\text { Poisson's coefficient of } \\
\text { rail }\end{array}$ & $v_{R}=0,30$ & $C_{s 23}=60 \mathrm{kNs} / \mathrm{m}$ & $C_{s 34}=50 \mathrm{kNs} / \mathrm{m}$ \\
\hline elastic modulus of rail & $E_{R}=206 \mathrm{GPa}$ & ballast stiffness coefficient: & $k_{s 11, i, j}=15 \mathrm{MN} / \mathrm{m}$ \\
\hline rail density & $\rho_{R}=7850 \mathrm{~kg} / \mathrm{m}^{3}$ & $k_{s 22, i, j}=16 \mathrm{MN} / \mathrm{m}$ & $k_{s 33, i, j}=17 \mathrm{MN} / \mathrm{m}$ \\
\hline rail mass per meter & $m_{R}=65 \mathrm{~kg} / \mathrm{m}$ & $k_{s 01}=180 \mathrm{MN} / \mathrm{m}$ & $k_{s 12}=170 \mathrm{MN} / \mathrm{m}$ \\
\hline pad damping coefficient & $C_{p a d}=45 \mathrm{kNs} / \mathrm{m}$ & $k_{s 23}=160 \mathrm{MN} / \mathrm{m}$ & $k_{s 34}=150 \mathrm{MN} / \mathrm{m}$ \\
\hline pad stiffness & $k_{p a d}=140 \mathrm{MN} / \mathrm{m}$ & ballast mass: & $m_{s 1}=500 \mathrm{~kg}$ \\
\hline sleeper spacing & $L_{p}=0,5435 \mathrm{~m}$ & $m_{s 2}=300 \mathrm{~kg}$ & $m_{s 3}=200 \mathrm{~kg}$ \\
\hline sleeper mass & $m_{s l}=265 \mathrm{~kg}$ & & \\
\hline $1 / 8$ car body mass & $m_{b g 4}=8743 \mathrm{~kg}$ & $\begin{array}{l}\text { car body damping coefficient } \\
\text { frame damping coefficient }\end{array}$ & $\begin{array}{c}C_{b g 4}=10 \mathrm{kNs} / \mathrm{m} \\
C_{b g 3}=100 \mathrm{kNs} / \mathrm{m}\end{array}$ \\
\hline $1 / 4$ bogie mass & $m_{b g 3}=700 \mathrm{~kg}$ & wheelset damping coefficient & $C_{b g 2}=50 \mathrm{kNs} / \mathrm{m}$ \\
\hline $1 / 2$ wheelset mass & $m_{b g 2}=640 \mathrm{~kg}$ & $\begin{array}{l}\text { damping coefficient of mass in } \\
\text { contact }\end{array}$ & $C_{b g 1}=44.2 \mathrm{kNs} / \mathrm{m}$ \\
\hline car body stiffness & $k_{b g 34}=2.55 \mathrm{MN} / \mathrm{m}$ & wheel Radius & $R_{W}=0.495 \mathrm{~m}$ \\
\hline frame stiffness & $k_{b g 23}=6.5 \mathrm{MN} / \mathrm{m}$ & elastic modulus of wheel & $E_{W}=210 \mathrm{GPa}$ \\
\hline wheelset stiffness & $k_{b g 12}=56 \mathrm{MN} / \mathrm{m}$ & Poisson's coefficient of wheel & $v_{W}=0.30$ \\
\hline $\begin{array}{l}\text { Maximal penetration } \\
\text { velocity }\end{array}$ & $\dot{\delta}_{\max }=10 \mathrm{~m} / \mathrm{s}$ & Restitution coefficient & $e=0.65$ \\
\hline exponent & $n=3 / 2$ & Friction coefficient & $\mu\left(\varepsilon_{\mathrm{e}, \mathrm{i}}\right)=0.3$ \\
\hline
\end{tabular}


The wheel profile with one flat $(\mathrm{L}=100 \mathrm{~mm})$ is presented in the Fig. 3. For the first time the wheel flat contacts with the rail during the period $t \in[0.08302, \ldots, 0.08493$. and lasts $0.00191 \mathrm{~s}$.

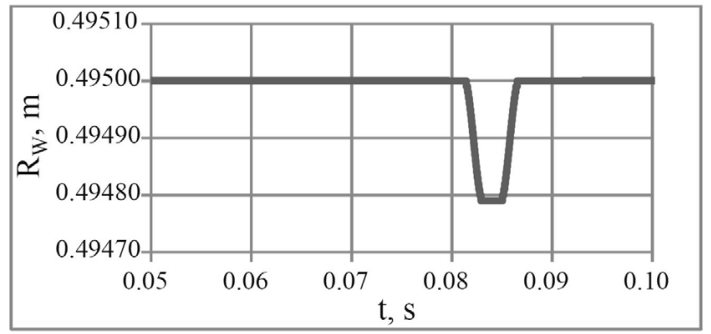

Fig. 3. Dependency of wheel profile

The unevenness of rail R-65 and wheel with flat are considered. Speed of the train is $100 \mathrm{~km} / \mathrm{h}$; static load on the rail is $100 \mathrm{kN}$. Change of the rail deflection in the centre of wheel and rail contact over time is shown in Fig. 4.
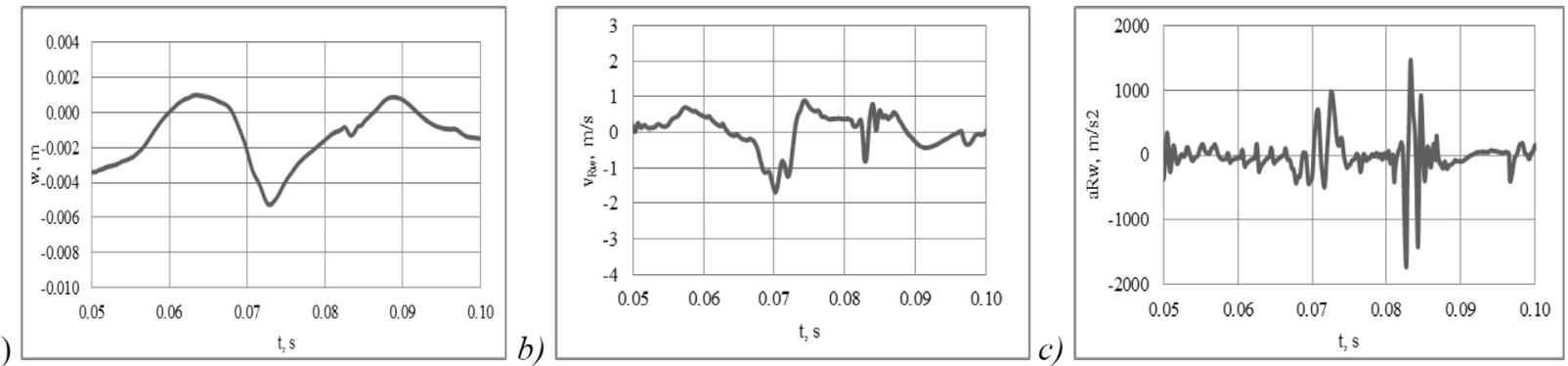

Fig. 4. a) Rails deflection in the centre of contact and it's a) velocity b) acceleration changes in time

In Fig. 5 the penetration of wheel- rail contact and the changes of its first and second fluxion over time, when impact emerges, are shown.
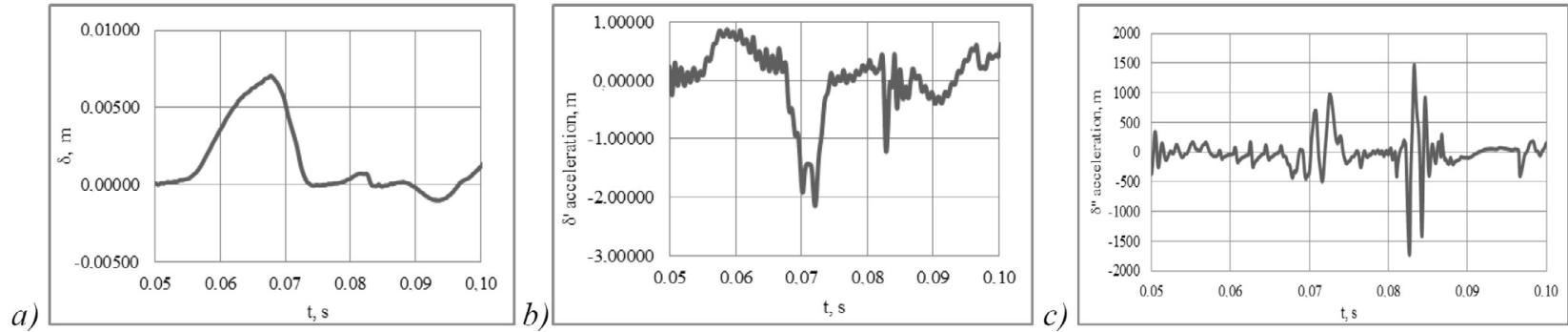

Fig. 5. Penetration, its first and second fluxion changes in time

Change of vertical force $F_{Z}$ operating upon wheel over time is shown in Fig. 6 . At the time of the first impact, the value of the short-term $(0.00191 \mathrm{~s})$ maximum vertical force operating in contact reaches $1.0 \mathrm{MN}$.

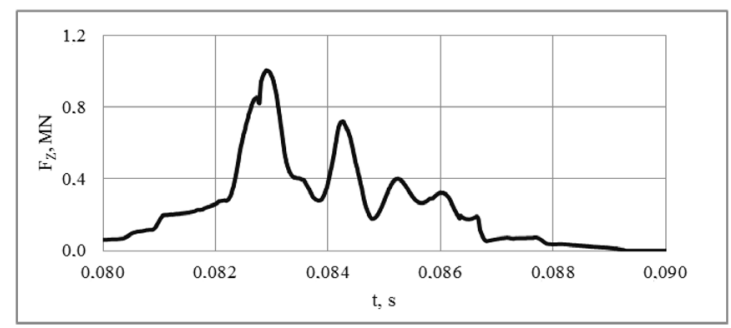

Fig. 6. Change of vertical force $F_{Z}$ operating upon the wheel over time 
Sleeper and 3 soil masses acceleration changes in time in dynamical system "railway wagontrack", when wagon wheelset wheel is with flat, is shown in Fig 7.

a)

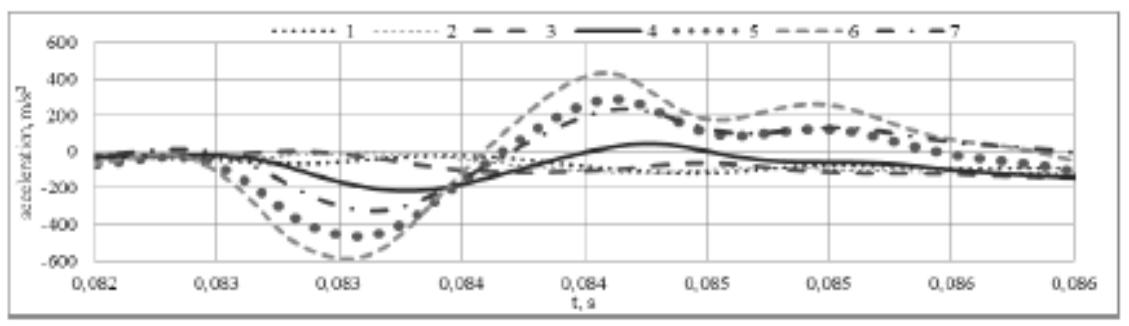

b)

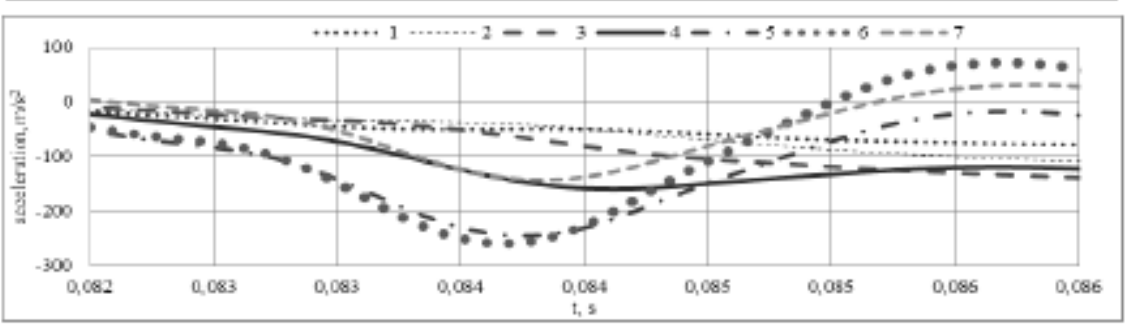

c)

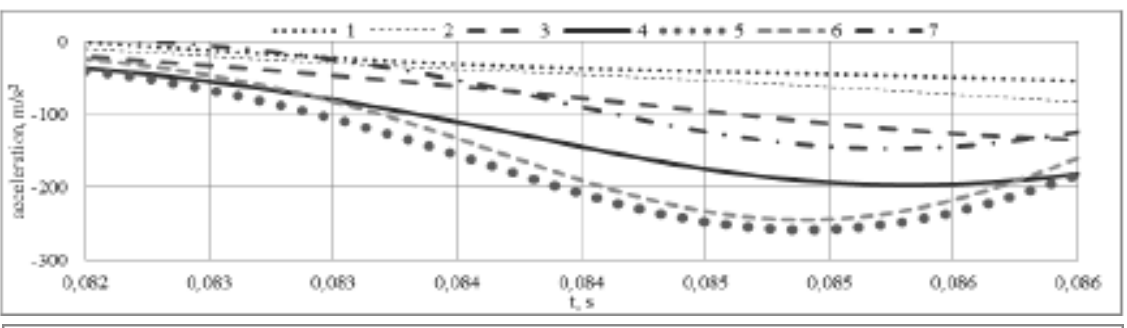

d)

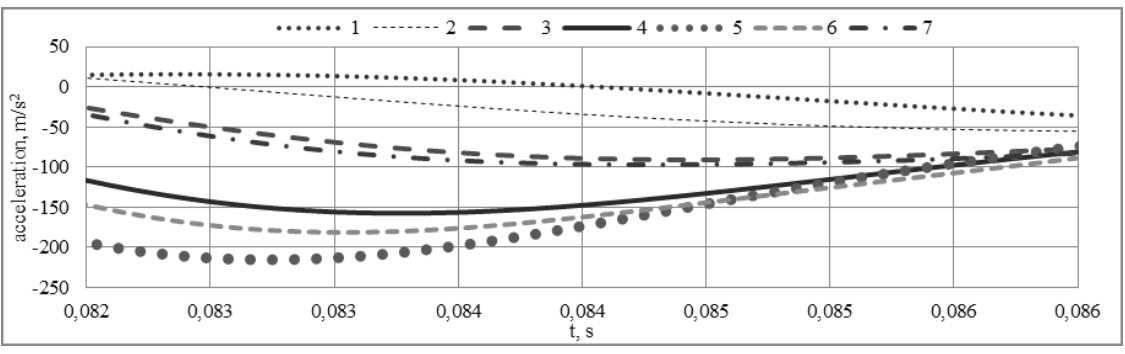

Fig. 7. Change of acceleration of the sleepers and soil layer upon time: a) sleepers), b) 1 soil layer, c) 2 soil layer, d) 3 soil layer

From Fig. 7 it is seen that the bigger the mass is the higher the changes are. The maximum acceleration dynamic is seen in the sleeper, because of its mass, that is lower than soil's.

\section{Conclusions}

The developed mathematical model of the system "Railway vehicle wheel-track" enables to examine the interaction between the wheel with flats and rail, to assess rail bed soil, sleepers and intermediary physical and mechanical properties, the wheel geometry, the wagon dynamic characteristics at different running speeds and sizes of the wheel flats.

A research of dynamic processes of the system "Railway vehicle wheel-track" with the wheel flat $\mathrm{L}=100 \mathrm{~mm}$, when the speed is $\mathrm{V}=100 \mathrm{~km} / \mathrm{h}$ and the wheel static load is equal to $0.1 \mathrm{MN}$.

Duration of hit is about $1.9 \mathrm{~ms}$, i.e. duration of contact is nearly equal to time during which the wheel set passes a half of the flat length $\mathrm{L} /(2 \mathrm{~V})$. During the hit, the wheel set contacts with the rail and the rail overlies the sleeper. Throughout this hit, force operating the wheelset is equal to approximately 1.0 MN. The value of contact forces depends on both physical-mechanical characteristics of the system "Railway vehicle wheel-track" and vertical acceleration values of the wheel set wheel during the impact. Maximum value of the sleeper acceleration is equal $410 \mathrm{~g}$. 


\section{Acknowledgements}

This work has been supported by the European Social Fund within the project "Development and application of innovative research methods and solutions for traffic structures, vehicles and their flows", project code VP1-3.1-ŠMM-08-K-01-020.

\section{References}

[1] Kumaran, G., Menon, D., Krishnan Nair, K., Dynamic studies of rail track sleepers in a track structure system, Journal of Sound and Vibration, Vol. 268, pp. 485-501, 2003.

[2] Nguyen, K., Goicolea, J. M., Galbadón, F., Dynamic effect of high speed railway traffic loads on the ballast track settlement, Actas del Congresso de Métodos Numéricos em Engenharia (14/06/2011 - 17/06/2011), P 19, Coimbra, Portugal 2011.

[3] Polach, O., A Fast Wheel-Rail Forces Calculation Computer Code, Proc. of the 16th IAVSD Symposium Pretoria, Vehicle System Dynamics, Supplement 33, pp. 728-739, 1999.

[4] Shen, Z. Y., Hedrick, J. K., Elkins, J. A., A Comparison of Alternative Creep Force Models for Rail Vehicle Dynamic Analysis, 8th IAVSD Symposium on Dynamics of Vehicles on Road and Tracks, Swets and Zeitlinger, pp. 591-605, Cambridge, Massachusetts 1983.

[5] Yih-Hwang, Lin, Vibration analysis of Timoshenko beams traversed by moving loads, Journal of Marine Science and Technology, Vol. 2, (1), pp. 25-35, 1994.

[6] Wu, T. X., Thompson, D. J., A double Timoshenko beam model for vertical vibration analysis of railway track at high frequencies, Journal of Sound and Vibration Vol. 224 (2), pp. 329-348, 1999.

[7] Coelho, B. E. Z., Hölscher, P., Barends, F. B. J., Dynamics of railway transition zones in railways, Geotechnical Engineering: New Horizons, pp. 133-139, 2011.

[8] Lundqvist, A., Larsson, R., Dahlberg, T., Influence of railway track stiffness variation on wheel/rail contact forces, Track for High-Speed Railways, Porto, Portugal 2006.

[9] Kaewunruen, S., Remennikov, A. M., Aikawa, A., Sakai, H., Free Vibrations of Interspersed Railway Track Systems in Three-Dimensional Space, Acoustics Australia 20, Vol. 42(1), pp. 20-26, Australia 2014.

[10] Zhai, W. M., Wang, K. Y., Lin, J. H., Modelling and experiment of railway ballast vibrations, Journal of Sound and Vibration Vol. 270(4-5), pp. 673-683, 2004.

[11] Sladkowski, A., Sitarz, M., Analysis of wheel-rail interaction using FE software, Wear Vol. 258(7-8), pp. 1217-1223, 2005.

[12] Knothe, K. L., Grassie, S. L., Railway track and vehicle/track interaction at high frequencies, Journal of Vehicles System Dynamics Vol. 22(3-4), pp. 209-262, 1993.

[13] Nielsen, J. C. O., Vertical dynamic interaction between train and track-influence of wheel and track imperfections, Journal of Sound and Vibration, Vol. 87 (5), pp. 825-839, 1995.

[14] Oscarsson, J., Dahlberg, T., Dynamic train/track/ballast interaction-computer models and full-scale experiments, Journal of Vehicle System Dynamics, Vol. 29(1), pp. 73-84, 2007.

[15] Ripke, B., Knothe, K., Simulation of high frequency vehicle-track interactions, Journal of Vehicle System Dynamics, Vol. 24(1), pp. 72-85, 1995.

[16] Zakharov, S., Zharov, Il., Simulation of mutual wheel/rail wear, Wear, Vol. 253(1-2), pp. 100106, 2002.

[17] Lia, X., Jina, X., Wena, Z., Cuib, D., Zhang, W., A new integrated model to predict wheel profile evolution due to wear, Wear, Vol. 271(1-2), pp. 227-237, 2011.

[18] Telliskivi, T., Simulation of wear in a rolling-sliding contact by a semi-Winkler model and the Archard's wear law, Wear, Vol. 256(7-8), pp. 817-831, 2004. 